\title{
Effects of basin parameters on the spatial variation of characteristics of basin generated Rayleigh waves
}

\author{
J. P. Narayan", P. K. Singh and Kamal
}

*Correspondence:

Department of Earthquake Engineering, Indian Institute of Technology Roorkee,

Roorkee 247667, India

\begin{abstract}
This paper presents the effects of shape of interface between the sediment and basement rock (SISB), basin-shape-ratio, impedance contrast, sediment-damping and angle of incidence of body waves on the characteristics of basin generated Rayleigh (BGR) waves and associated spatial variations of average spectral amplification (ASA), differential ground motion (DGM) and average aggravation factor (AAF) in the considered $2 \mathrm{D}$ basin models. The seismic responses of various basin models were simulated using recently developed viscoelastic P-SV wave fourth-order spatial accurate staggeredgrid finite-difference algorithm. It is inferred that the SISB has a major impact on the characteristics of the BGR-waves in basin. The obtained largest and least ASA, DGM and AAF were in the basins with SISB as triangular and trapezoidal, respectively. An increase of ASA, AAF and DGM were obtained with an increase of impedance contrast, sediment quality factor, basin shape-ratio and angle of incidence of body wave. It is also inferred that the generated Rayleigh wave in the rocky area in case of plane wave front with inclination $45^{\circ}$ and thereafter their transmission in the basin is responsible for the unexpected AAF of the order of 4.7 in the circular basin.
\end{abstract}

Keywords: Basin effects, Basin-generated Rayleigh waves, Aggravation factor, Differential ground motion and finite difference simulation

\section{Background}

Seismic microzonation (the division of large area of interest into small sectors in which a particular seismic or geotechnical parameter is on an average similar everywhere is defined as seismic microzonation) of an area is very much essential for the minimization of the impact of earthquake hazard, prediction of seismic risk and cost effective earthquake engineering. A highly variable damage pattern has been reported in a particular basin due to the physical phenomenon like double-resonance [1, 2], basin generated surface waves [3-9], basement focusing effects [10-12] and basin-transduced surface waves [13-16]. Basin generated surface waves were confirmed in the Santa Monica and Kobe basins based on the recorded ground motion, theoretical studies and the observed damages during the 1994 Northridge earthquake and 1995 Kobe, earthquake $[4,6,9]$. There are other numerous consistent macro-seismic observations showing a significant increase in damage severity in narrow zones located near the basin-edge [17]. Various scientists have studied the effects of soil layering on the characteristics of

c) 2016 The Author(s). This article is distributed under the terms of the Creative Commons Attribution 4.0 International License (http://creativecommons.org/licenses/by/4.0/), which permits unrestricted use, distribution, and reproduction in any medium, provided you give appropriate credit to the original author(s) and the source, provide a link to the Creative Commons license, and indicate if changes were made. 
basin generated surface waves $[8,18]$. Bard and Bouchon [3] reported preferential surface wave generation in case of larger angle of incidence of body wave at the basin edge.

The current practice of seismic microzonation in most of the countries is to transfer the bedrock motion to the surface using 1D S-wave response of a soil column. Based on the theoretical studies, it was inferred that 1D response was inadequate to explain the observed damages in the Santa Monica during the 1994 Northridge earthquake [4] and in the Kobe basin during the 1995 Kobe, Japan earthquake [9]. To incorporate the 2D/3D complex site effects in seismic microzonation, Chavez-Garcia and Faccioli [19] have proposed the term aggravation factor (aggravation factor is simply the extra spectral amplification due to the complex 2D/3D site effects over the 1D response of a soil column). The differential ground motion (DGM) caused by surface waves has an important effect on the response of lifelines, such as pipelines, bridges and communication transmission systems. The DGM induces significant additional stresses in the structures than the ones induced if the motions at the supports were considered to be identical. In the basins, an important cause for the spatial variation of seismic ground motions is the basin generated surface wave.

It is well known that most of the existing basins on the globe are 2D in natures. So, 2D response across the basin is sufficient enough to predict the characteristics of the basin generated surface waves and there is no need of computation of 3D response of such basins. Further, the computation of 3D responses of such 2D basins seems to be impossible considering the current computational facility available. However, the shape of interface between the sediment-deposit and the basement (SISB) may vary from basin to basin and location to location in such 2D basins. Further, such 2D basins may have any shape-ratio (ratio of maximum depth of basin to its half-width). Considering the existence of plenty of 2D basins in nature, the first author of this paper and his co-researchers have studied the effects of various factors like edge-slope [7], sediment layering in basin $[8,20]$, impedance contrast and damping [21] on the characteristics of the basin generated surface waves in 2D open basins (open basin means the second edge of basin is at an infinite distance). In contrast to open basin, Narayan and Richhariya [22] considered a closed rectangular basin and computed the characteristics of the basin generated Love waves. Narayan [23] also studied the effects of angle of incidence of the SH-wave on the characteristics of basin generated Love waves in a closed.

In all the above mentioned studies by the first author and his co-researchers, sediment damping was applied corresponding to the dominant frequency only (means no frequency dependent damping) and there is no study on the P-SV wave simulation of a closed basin, which may cause basin generated Rayleigh (BGR) waves. For example, in this study dominant frequency is $4.0 \mathrm{~Hz}$ and the frequency bandwidth is $0-10 \mathrm{~Hz}$. It means, all the frequency larger than $4.0 \mathrm{~Hz}$ and lesser than $4.0 \mathrm{~Hz}$ will be under damped and over damped, respectively. Furthermore, surface waves are more affected by the sediment damping as compared to the body waves since they entirely travel back and forth in a closed basin. So, the realistic characteristics of the basin generated surface waves and associated DGM could not be predicted in a closed basin if damping is applied only at the dominant frequency $[7,22,23]$. In order to predict the realistic characteristics of the BGR-wave and associated DGM in a closed basin, the seismic responses of various considered basin models were simulated using a recently developed P-SV wave viscoelastic 
fourth-order accurate time-domain finite-difference (FD) algorithm by Narayan and Kumar [12]. This algorithm is efficient enough to incorporated the frequency-dependent as well as phase-dependent damping in a time-domain simulation. The effects of SISB, shape-ratio, impedance contrast (IC) sediment-damping and angle of incidence of body waves on the characteristics of BGR-waves and associated spatial variations of average spectral amplification (ASA), DGM and average aggravation factor (AAF) in the basins are studied in details. Snapshots have also be computed for inferring the development of BGR-waves and their back and forth propagation in the basin.

\section{Salient features of the used P-SV wave FD program}

A fourth-order accurate computer program developed by Narayan and Kumar [12] which is based on the staggered-grid finite-difference approximation of the viscoelastic P-SV wave equation for the heterogeneous anelastic medium is used for simulation of responses of various considered models. The frequency-dependent damping in the time-domain FD simulations is incorporated based on the GMB-EK rheological model [24]. A material independent anelastic function developed by Kristek and Moczo [25] was used since it is preferable in case of material discontinuities in the FD grid [12, 26]. The required unrelaxed moduli (Tables 1,2 ), as input parameters, are computed with the help of P-wave and S-wave velocities and respective quality factors measured in field using a particular reference frequency $\left(F_{r}\right)\left(F_{r}\right.$ is assumed as $1.0 \mathrm{~Hz}$ here). First, anelastic coefficients are computed for respective waves using respective quality factor, Futtermann relation [27] and least square technique as optimization methodology. Then, the computed anelastic coefficient are used to compute unrelaxed moduli using equations (7)-(9) of Narayan and Kumar [12]. The sponge boundary condition [28] is implemented on the model edges to avoid the edge reflections [29]. In order to avoid the

Table 1 The velocities and quality factors at reference frequency $1.0 \mathrm{~Hz}$, density and unrelaxed moduli for the sediment and rock

\begin{tabular}{lcccccc}
\hline Model & Vs $(\mathbf{m} / \mathbf{s})$ & $\mathbf{V p}(\mathbf{m} / \mathbf{s})$ & Density $(\mathbf{g} / \mathbf{c c})$ & $\mathbf{Q}_{\mathbf{p}}=\mathbf{Q}_{\mathbf{s}}$ & \multicolumn{2}{l}{$\begin{array}{l}\text { Unrelaxed moduli } \\
\text { (GPa) }\end{array}$} \\
\cline { 6 - 8 } & & & & & $\boldsymbol{\mu}_{\mathbf{u}}$ & $\boldsymbol{\lambda}_{\mathbf{u}}$ \\
\hline Sediment & 500 & 971 & 2.00 & 50 & 0.5199 & 0.8841 \\
Rock & 1800 & 3114 & 2.40 & 180 & 7.860 & 7.697 \\
\hline
\end{tabular}

Table 2 The velocities and quality factors at reference frequency $1.0 \mathrm{~Hz}$, density, IC and unrelaxed moduli for the ICM1-ICM4 basin models

\begin{tabular}{|c|c|c|c|c|c|c|c|}
\hline \multirow[t]{2}{*}{ Model } & \multirow[t]{2}{*}{ Vs $(\mathrm{m} / \mathrm{s})$} & \multirow[t]{2}{*}{$\mathrm{Vp}(\mathrm{m} / \mathrm{s})$} & \multirow[t]{2}{*}{ Density (g/cc) } & \multirow[t]{2}{*}{ IC } & \multirow[t]{2}{*}{$Q_{P}=Q_{S}$} & \multicolumn{2}{|c|}{$\begin{array}{l}\text { Unrelaxed Moduli } \\
\text { (GPa) }\end{array}$} \\
\hline & & & & & & $\mu_{u}$ & $\lambda_{u}$ \\
\hline ICM1 & 500 & 971 & 2.00 & 4.32 & 50 & 0.5199 & 0.8841 \\
\hline ICM2 & 650 & 1263 & 2.05 & 3.24 & 65 & 0.8925 & 1.536 \\
\hline ICM3 & 800 & 1555 & 2.10 & 2.57 & 80 & 1.377 & 2.387 \\
\hline ICM4 & 950 & 1846 & 2.15 & 2.11 & 95 & 1.980 & 3.443 \\
\hline Rock & 1800 & 3114 & 2.40 & - & 180 & 7.860 & 7.697 \\
\hline
\end{tabular}


thickness discrepancy of the first sediment layer, which causes an increase of value of the numerically computed fundamental frequency, VGR-stress imaging technique proposed by Narayan and Kumar [30] is used.

\section{Effects of SISB}

To study the effects of shape of interface between the sediment and the underlying basement rock (SISB) on the characteristics of the BGR-waves, four 2D basin models namely semi-circular (CRBM), rectangular (REBM), triangular (TRBM) and trapezoidal (TPBM) are considered whose SISB are semi-circular, rectangular, triangular and trapezoidal, respectively. The north-south cross sections of the CRBM, REBM, TRBM and TPBM basin models are shown in Fig. 1a-d, respectively. The remaining geometrical parameters like width $(3000 \mathrm{~m})$, maximum depth of sediment $(200 \mathrm{~m})$ and inelastic parameters of the sediment and rock are the same for all the models. All the distances are measured with respect to the centre of basins. A horizontal plane wave front has been generated at a depth of $300 \mathrm{~m}$ using various point sources along a horizontal line. The point source has been generated by using the shear stress $\left(\sigma_{\mathrm{xz}}\right)$ in the form of Ricker wavelet. The dominant frequency in the considered Ricker wavelet was $4.0 \mathrm{~Hz}$ and frequency bandwidth $0-10 \mathrm{~Hz}$. Seismic responses have been computed at 41 equidistant (100 m apart)

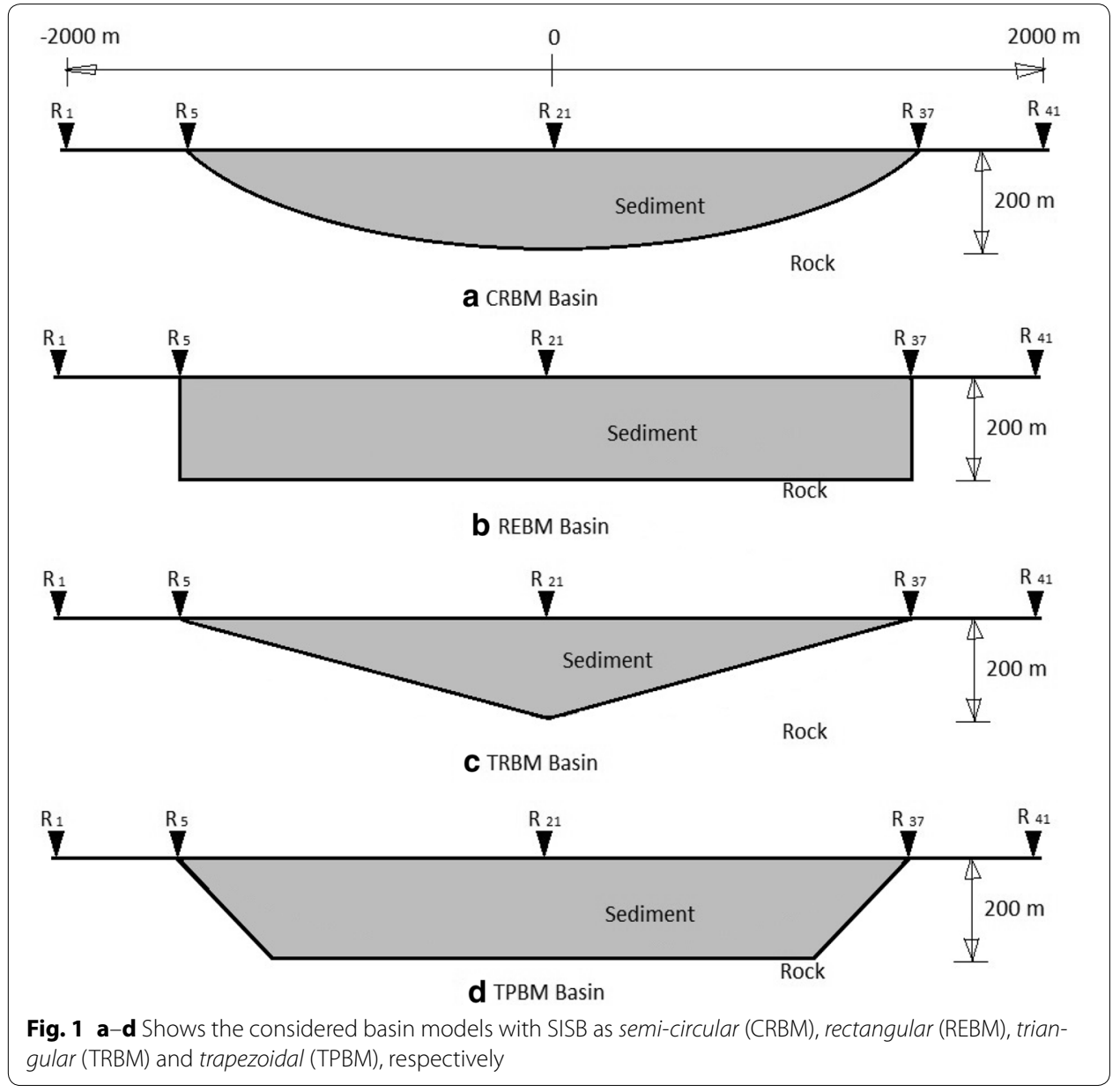


receiver points, extending $2000 \mathrm{~m}$ south to $2000 \mathrm{~m}$ north of centre of the basins. Four relaxation frequencies as $0.02,0.2,2.0$ and $20.0 \mathrm{~Hz}$ were used for the computations of the unrelaxed moduli. The velocities and quality factors for the P- and S-waves at a reference frequency $(\mathrm{Fr}=1.0 \mathrm{~Hz})$, density and unrelaxed Lame's parameter ' $\lambda$ ' and ' $\mu$ ' for the sediment and rock are given in Table 1 . To reduce the requirement of computational time and memory, the basin models have been descritised with a continuous variable grid size [30]. The vertical grid size was $5 \mathrm{~m}$ from free surface to a depth of 265 and $15 \mathrm{~m}$ thereafter. Similarly, in the horizontal direction, the grid size is $5 \mathrm{~m}$ from $2100 \mathrm{~m}$ south to $2100 \mathrm{~m}$ north of centre of basins and $15 \mathrm{~m}$ thereafter. The time step is chosen to be $0.001 \mathrm{~s}$ to avoid stability problem. The seismic response of the model with no sediment is also computed for the quantification of spectral amplifications.

Figure 2a-d shows horizontal and vertical components of responses of the CRBM, REBM, TRBM and TPBM basin models, respectively. Incident SV-wave, its multiples and the BGR-waves are first, second and third arrivals in chronological order. The fundamental and first modes of the BGR-waves are generated in all the basins but their amplitudes are highly variable with change of SISB. The vertically polarized fundamental mode is slower than the horizontally polarized first mode of the BGR-wave. Very large amplitude at the centre of basin in horizontal component may be due to constructive interference of the BGR-waves generated at left and right edges of basin. No amplitude in the vertical component in trace recorded at centre of basin may be due to normal incidence of SV-wave and opposite polarity of the BGR-waves generated at left and right edges. A leakage of the BGR-wave in the rock can be inferred at each reflection of the BGR-wave at the basin-edge. Further, it appears that the dispersion of BGR-waves also depends on the SISB. It may be concluded that SISB plays an important role in deciding the characteristics of the BGR-waves.

\section{Snapshots}

In order to further infer the development of BGR-waves in a basin and their back and forth propagation in basin, snapshots in a rectangular area in the CRBM basin has been computed at different moments. The considered rectangular area extends $2000 \mathrm{~m}$ south to $2000 \mathrm{~m}$ north of centre of basin and from free surface to a depth of $360 \mathrm{~m}$. Figures 3 and 4 show the snapshots at different times for the horizontal and vertical components, respectively. The snapshots at times 0.3 to $1.3 \mathrm{~s}$ depict that the incident plane wave front of the SV-wave, it's multiple and generation and propagation of the BGR-waves towards the centre of basin. Similarly, snapshots at times 1.5 to $2.5 \mathrm{~s}$ depict the back and forth propagation of the BGR-waves in the CRBM basin.

\section{Average spectral amplification}

The spectral amplifications were computed just by taking the ratio of spectra of responses with and without basin in the model. The spectral ratio has been used to compute the average spectral amplification (ASA) at a particular location for a particular component in a desired frequency bandwidth $(0-10.0 \mathrm{~Hz})$. Further, ASA for the vertical component has been computed using the spectral ratio of vertical component of response of basin model with the horizontal component of response of half-space (in absence of basin). Figure 5a illustrates the comparison of spatial variation of ASA 


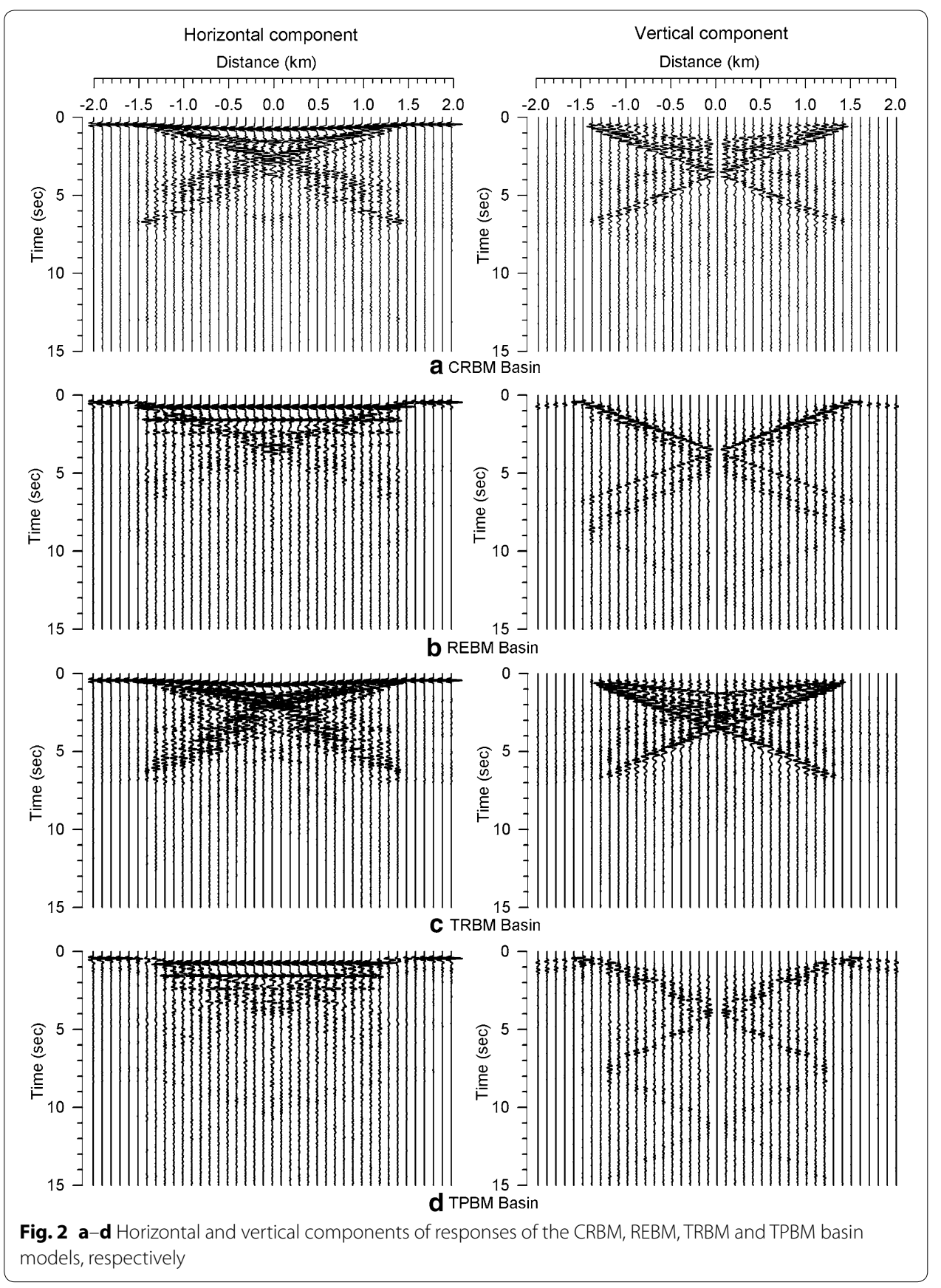

in different basins. An analysis of this figure reveals that the largest and lowest ASA are obtained in the TRBM and TPBM basins, respectively. Further, very large ASA is obtained near the basin edge of the REBM and TPBM basins, particularly in the vertical component [31]. On the other hand, largest ASA in the CRBM and TRBM basins are occurring at the centre of basin. 


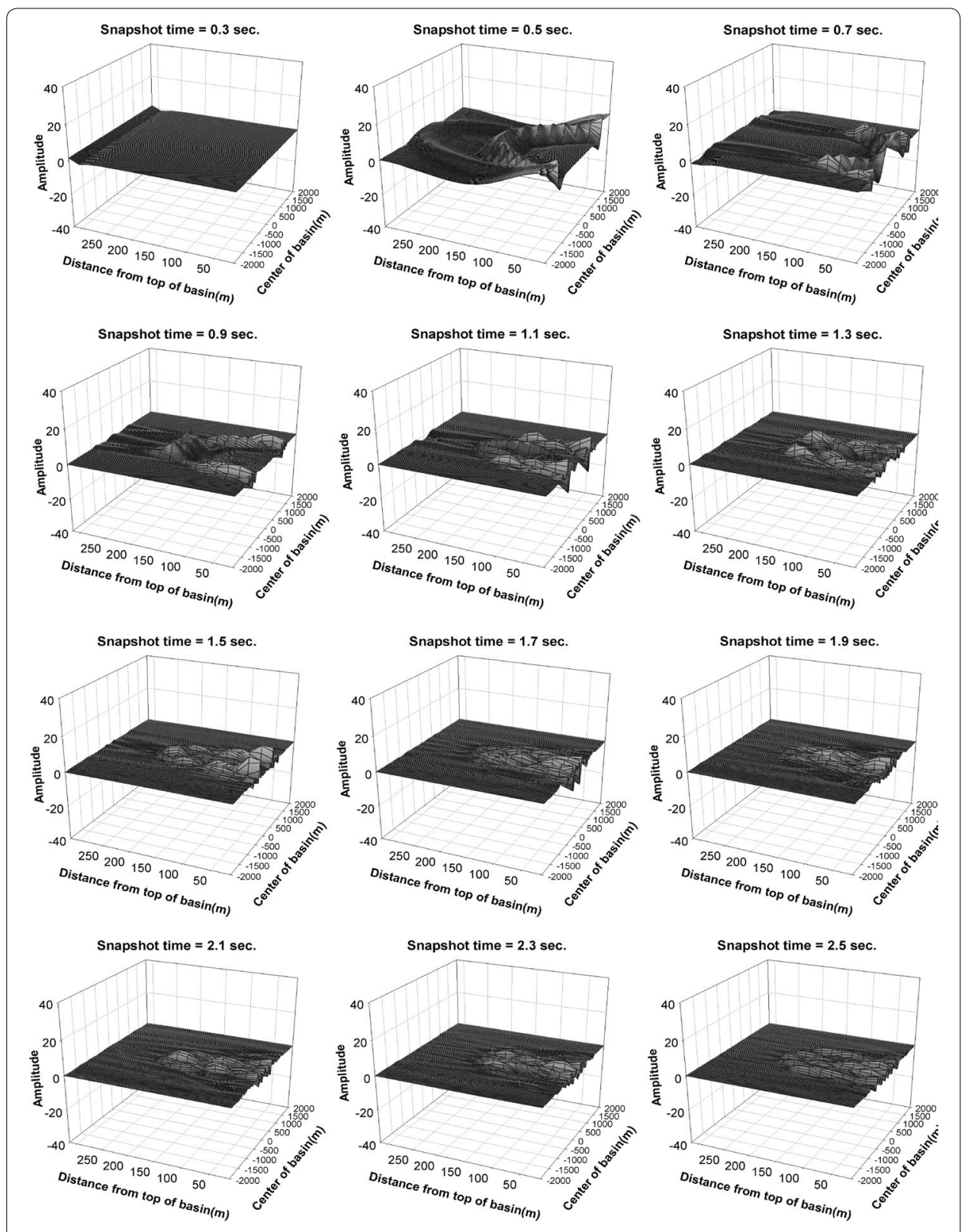

Fig. 3 Snapshots of the horizontal component of response of the CRBM basin at different moments

\section{Differential ground motion}

The differential ground motion (DGM) has been computed just by taking the difference of ground motion normalized with the distance between them. In order to get the DGM for a unit amplitude of the incident SV-wave, all the seismic responses has been normalized with the maximum amplitude of the SV-wave at the exposed rock in the horizontal component. Figure $5 \mathrm{~b}$ shows the comparison of spatial variation of the maximum DGM caused by the horizontal and vertical components of ground motion in the considered basins. The large DGM was obtained near the edges in the REBM and TPBM basins and near the edges as well as at the centre of the CRBM and TRBM basins. Although, maximum amplitude of the BGR-wave was obtained at the centre of basin due to the 


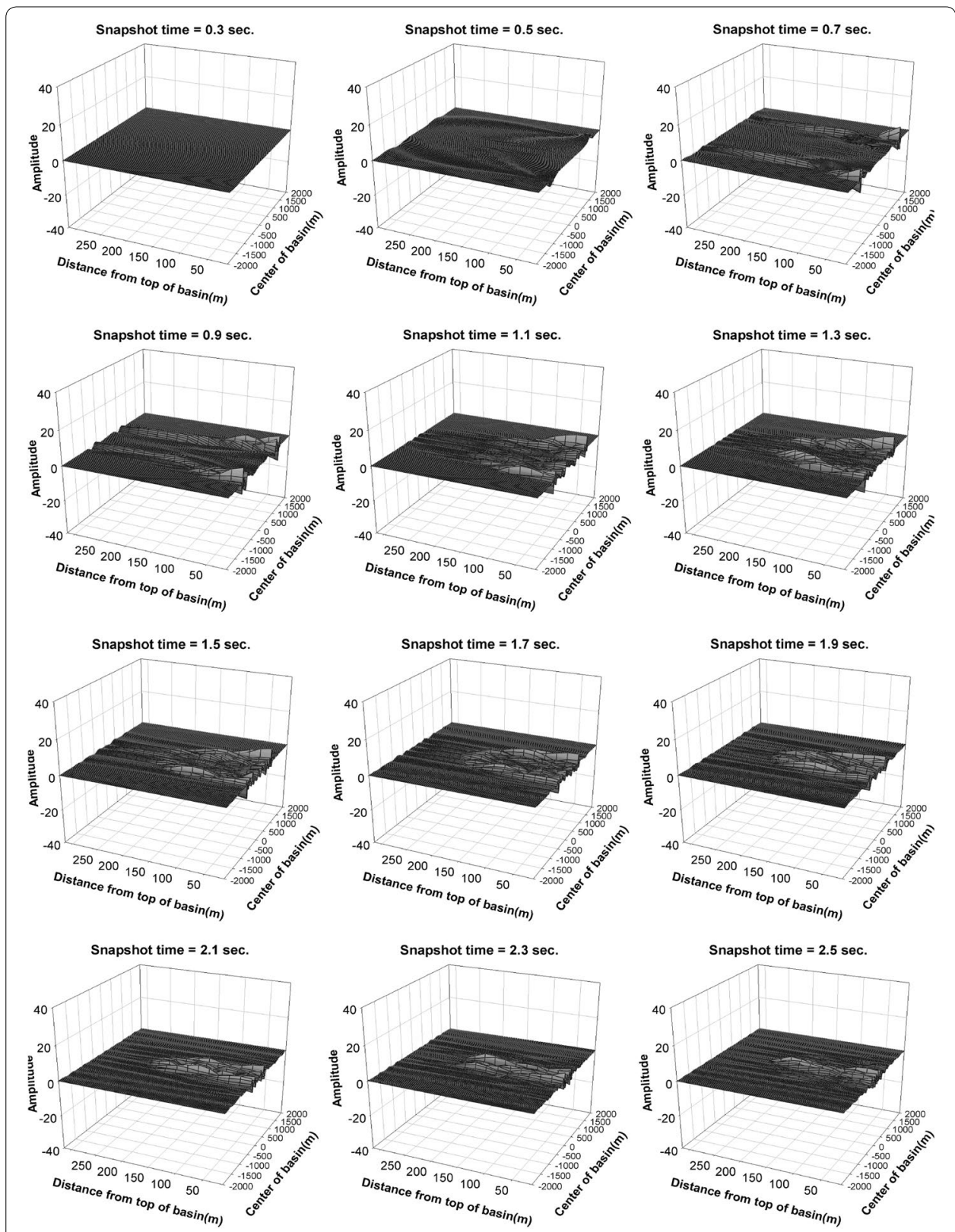

Fig. 4 Snapshots of the vertical component of response of the CRBM basin at different moments

interference of the horizontally travelling BGR-waves. The obtained largest DGM was at the centre of TRBM basin and least was at the centre of TPBM basins. The DGM in the horizontal component is larger than in the vertical component.

\section{Average aggravation factor}

In order to study the effects of shape of basins on the spatial variation of average aggravation factor (AAF), spectral aggravation factors were computed just by taking the spectral ratio of $2 \mathrm{D}$ response with the $1 \mathrm{D}$ response of the model at a particular location. Then spectral aggravation factors were used to find out the AAF at different locations in the basins. Figure $5 \mathrm{c}$ shows the comparison of spatial variation of AAF caused by the 

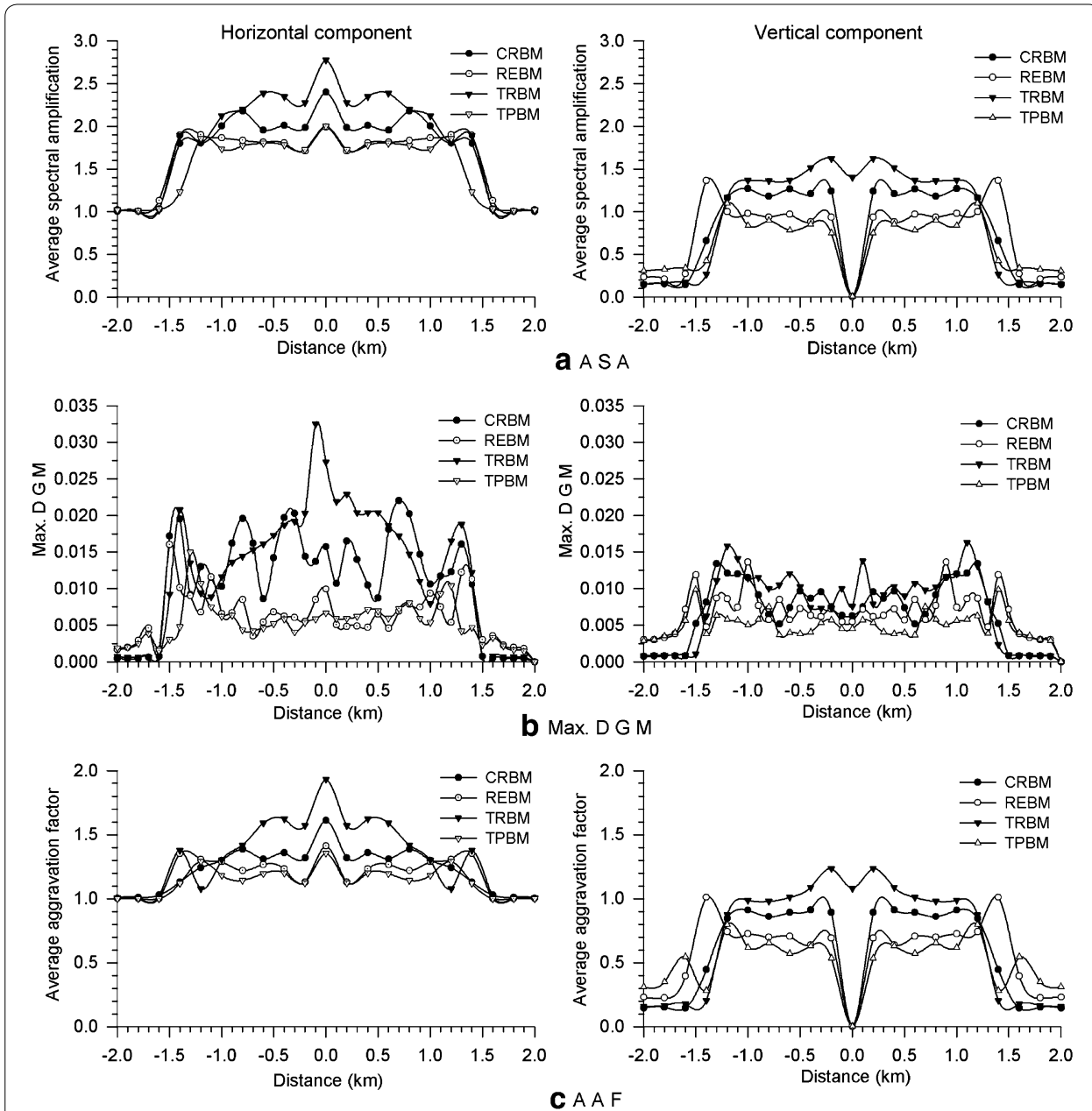

Fig. 5 a-c Spatial variation of $A S A$, maximum DGM and $A A F$, respectively in the CRBM, REBM, TRBM and TPBM basin models

BGR-waves in the horizontal and vertical components. Analysis of this figure depicts that the trends of spatial variation of AAF is almost the same as that of ASA in different basins. The largest AAF of the order of 1.9 was obtained at the centre of the TRBM basin in the horizontal component. The cause of increase of AAF towards the centre of basins may be the interference of the BGR-waves near the centre. It can be inferred that very large damage may occur in the central part of the TRBM and CRBM basins and near the edges of the REBM and TPBM basins. Finally, it may be concluded that SISB may play a major role in damage distribution pattern in the $2 \mathrm{D}$ basins. However, the effects of shape-ratio, IC, damping and angle of incidence of SV-waves on the characteristics of the BGR-waves have been studied in the CRBM basin only, considering that most of the basins in nature have shape of basement very similar to it.

\section{Effects of shape ratio of basin}

The shape-ratio of basin has been changed by changing the depth as well as width of the basin. The effects of shape-ratio on the ground motion characteristics for both the cases have been studied. First, seismic responses of the four semi-circular CRDM1-CRDM4 
basin models with maximum depth of sediment as 50,100, 150 and $200 \mathrm{~m}$ and a fixed width as $3000 \mathrm{~m}$ with shape-ratios as $0.03,0.06,0.10$ and 0.13 , respectively have been computed. The seismic responses of the another four basin CRWM1-CRWM4 models with width as 2000, 2500, 3000 and $3500 \mathrm{~m}$ and a fixed maximum depth as $200 \mathrm{~m}$ with shape-ratios as $0.20,0.16,0.13$ and 0.11 , respectively have also been computed. So, finally the range of basin-shape-ratio is $0.03-0.2$. Figure $6 \mathrm{a}-\mathrm{d}$ shows the seismic responses of the CRDM1-CRDM4 basin models, respectively. The characteristics of the body wave multiples and the BGR-waves are highly variable with the change of shaperatio of basin. A comparison of spatial variations of ASA, maximum DGM and AAF in

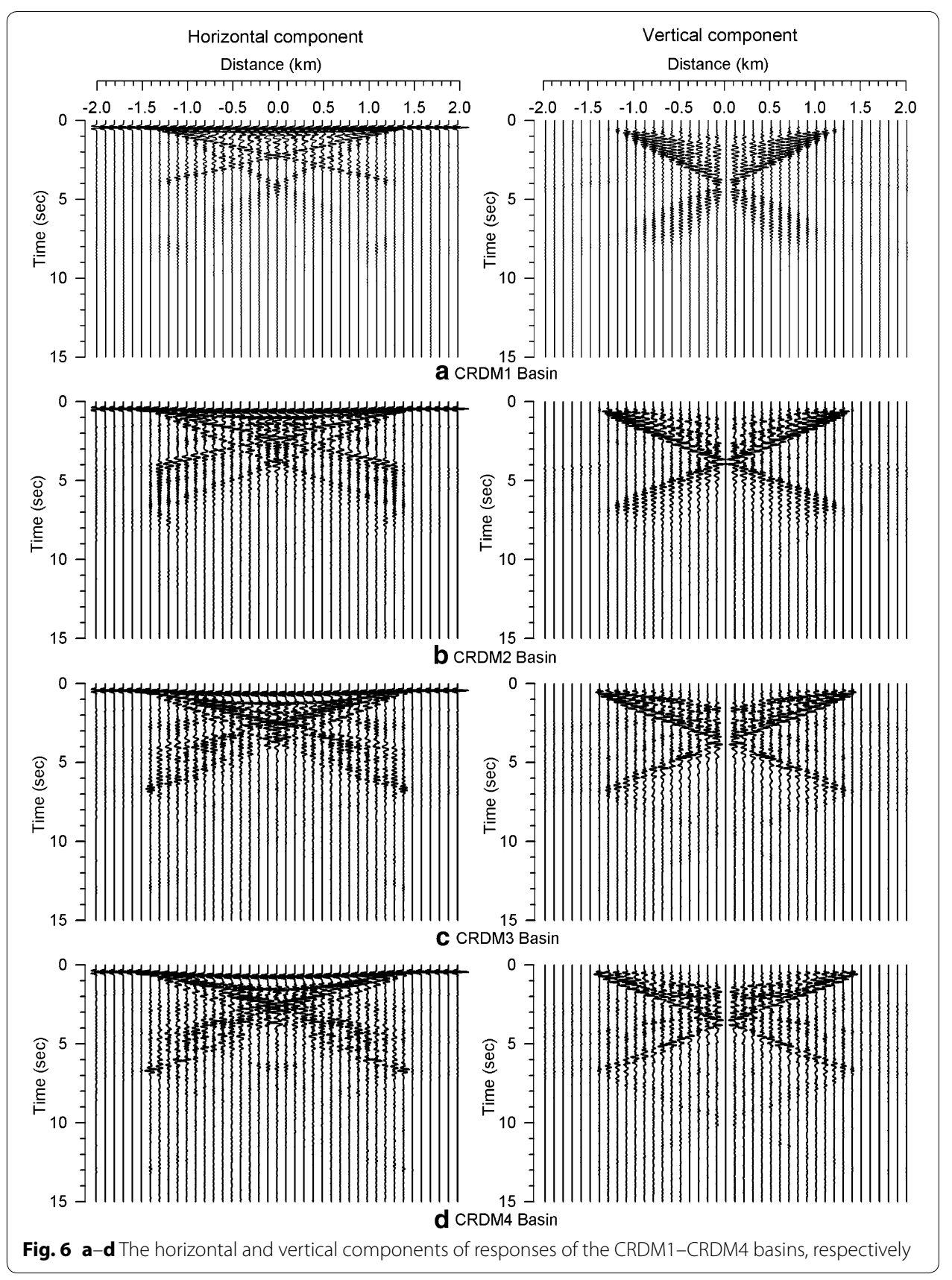


the CRMD1-CRDM4 basins are given in Fig. 7. On an average, an increase of ASA/AAF with an increase of shape-ratio can be inferred for the considered model parameters and frequency bandwidth. Similarly, a comparison of spatial variation of ASA, maximum DGM and AAF in the CRWD1-CRWM4 basins are given in Fig. 8. An increase of ASA/ AAF with an increase of shape-ratio can also be inferred, except in the CRWM1 basin with shape-ratio 0.2. So, it may be concluded that AAF/ASA and DGM in the horizontal component increases with the increase of shape-ratio of the semicircular basin, if shaperatio is less than 0.16 .

\section{Effects of impedance contrast and sediment-damping}

In this sub-section, the effects of impedance contrast (IC) and sediment-damping on the ground motion characteristics in the basin are documented. The velocities and quality factors at reference frequency, density and unrelaxed moduli for the ICM1-ICM4 basin models with difference IC are given in Table 2. The width and maximum depth of the semi-circular ICM1-ICM4 basins was taken as 3000 and $200 \mathrm{~m}$, respectively. Figure $9 \mathrm{a}-\mathrm{c}$ shows the spatial variation of ASA, maximum DGM and AAF in the horizontal and vertical components, respectively. An increase of ASA, maximum DGM and AAF

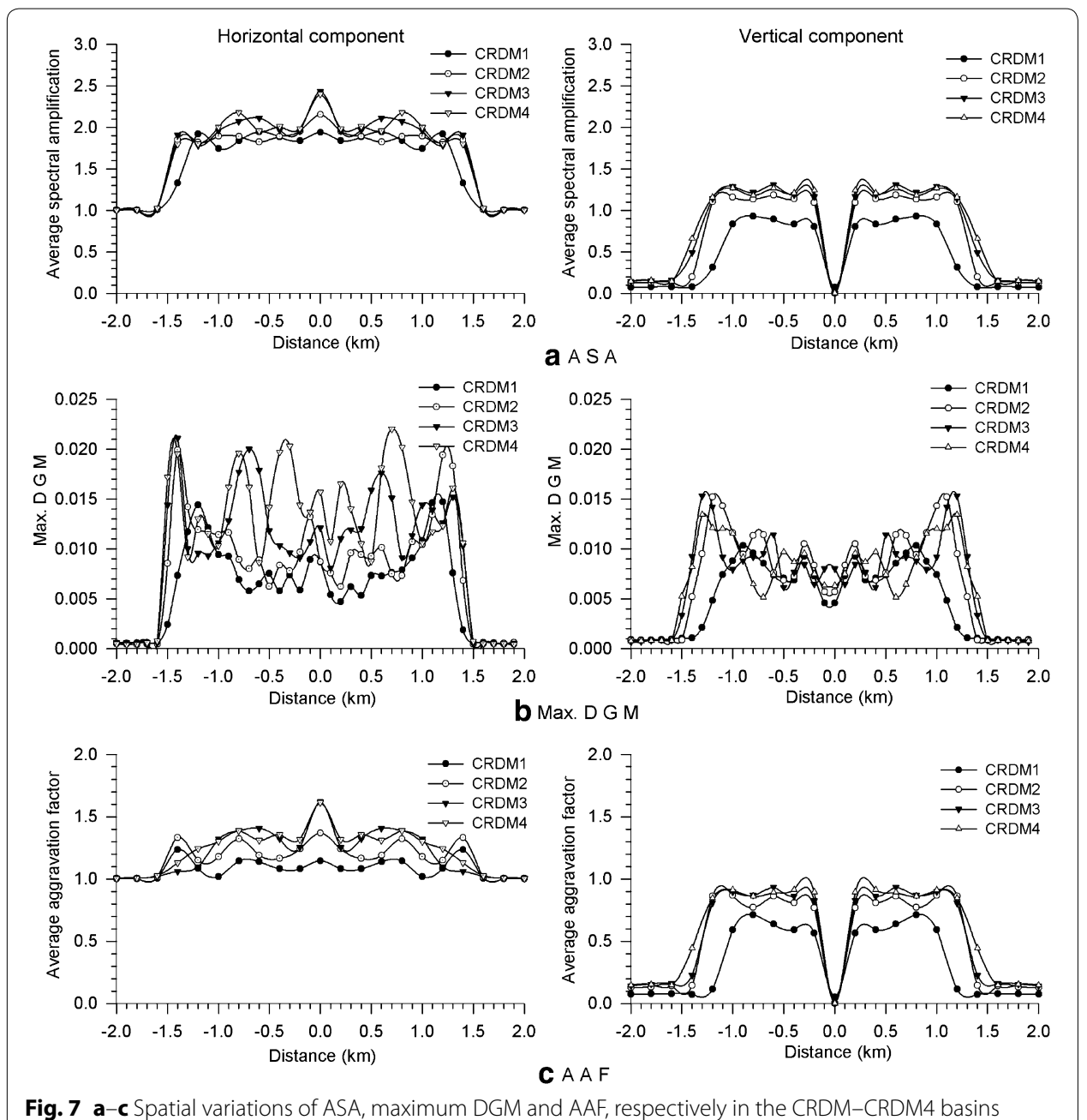



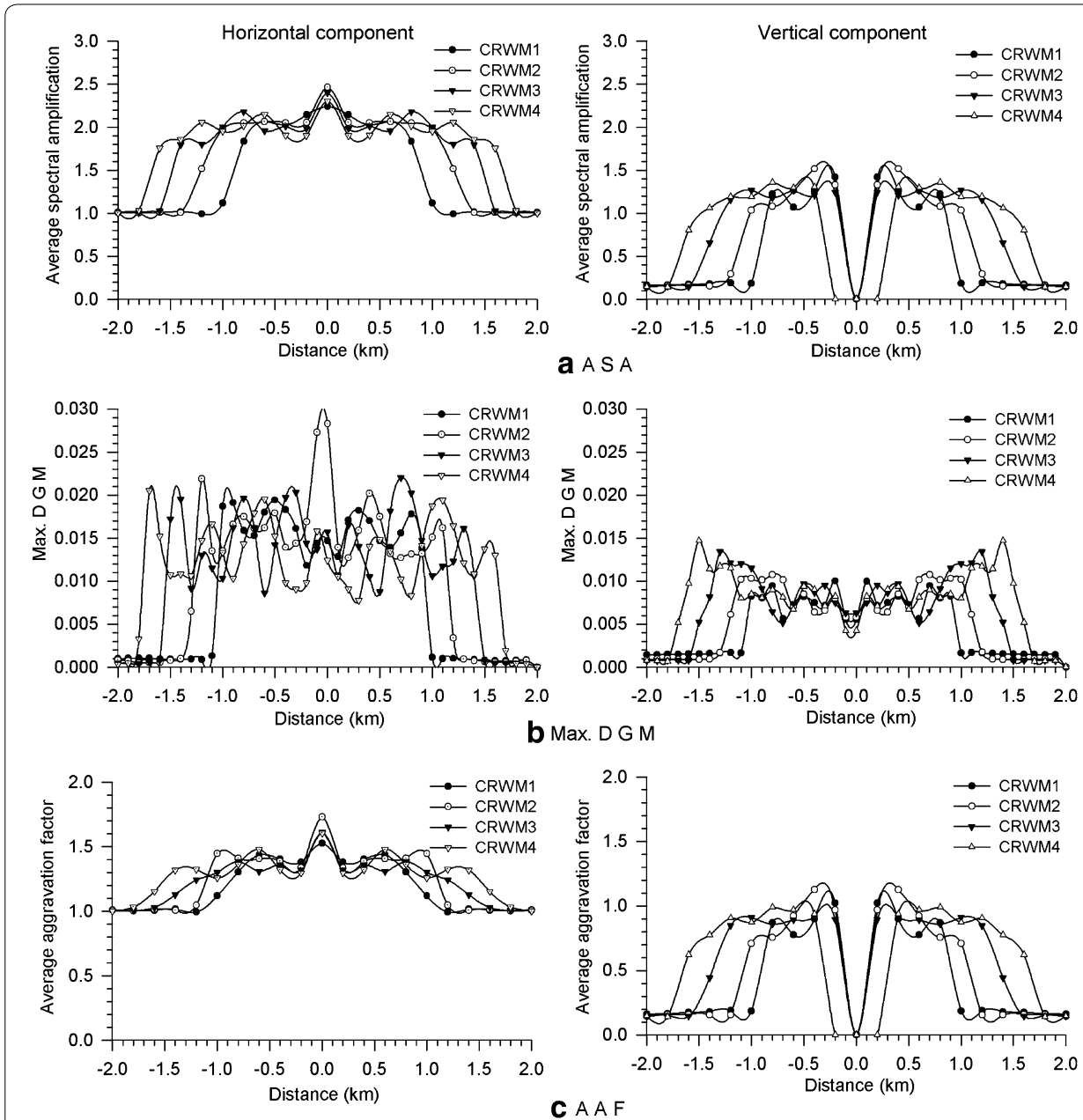

Fig. 8 a-c Spatial variations of ASA, maximum DGM and AAF, respectively in the CRWM1-CRWM4 basins

with an increase of IC can be inferred in both the horizontal and vertical components. Further, the ups and down are increasing with an increase of IC due to the development of more and more low frequency BGR-waves. The interference of these lower frequency BGR-waves is responsible for the large ASA/AAF at the centre of basin with a large IC. The obtained AAF at the centre of the ICM1-ICM4 basins are 1.60, 1.48, 1.20 and 1.05 for IC as 4.32, 3.24, 2.57 and 2.11, respectively.

To study the effects of sediment-damping on the ground motion characteristics, seismic responses of the four semi-circular BDM1-BDM4 basin models were computed for different-sediment damping. The velocities at reference frequency and density are the same as given Table 1. The quality factors at reference frequency and unrelaxed moduli for the different BDM1-BDM4 basin models are given in Table 3. The width and maximum depth of the semi-circular BDM1-BDM4 basins was also taken as 3000 and $200 \mathrm{~m}$, respectively. Figure 10a-c shows the spatial variation of ASA, maximum DGM and AAF in the horizontal and vertical components, respectively. An increase of ASA, maximum DGM and AAF with an increase of quality factor can be inferred in both the horizontal and vertical components. The larger increase of AAF towards the centre of basin as 

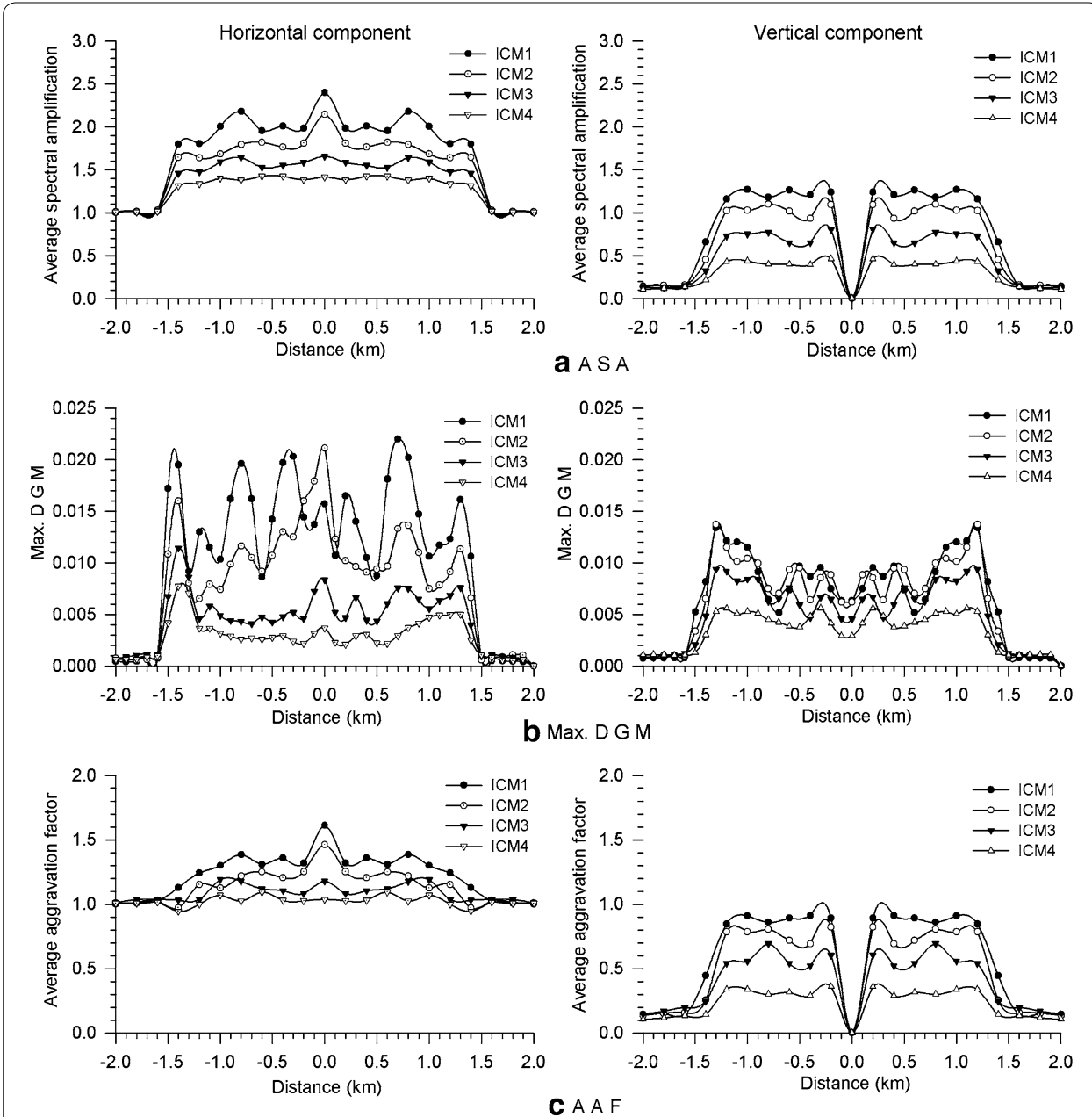

Fig. 9 a-c Spatial variations of ASA, maximum DGM and AAF, respectively in the ICM1-ICM4 basins

Table 3 The quality factors at reference frequency $1.0 \mathrm{~Hz}$ and unrelaxed moduli for the BDM1-BDM4 basin models

\begin{tabular}{lllll}
\hline Parameters & BDM1 & BDM2 & BDM3 & DBM4 \\
\hline $\mathrm{Q}_{\mathrm{p}}=\mathrm{Q}_{\mathrm{S}}$ & 25 & 37.5 & 50 & 62.5 \\
Unrelaxed moduli (GPa) & & & & \\
$\mu_{\mathrm{u}}$ & 0.5408 & 0.5271 & 0.5190 & 0.5159 \\
$\lambda_{\mathrm{u}}$ & 0.8823 & 0.8824 & 0.8841 & 0.8843 \\
\hline
\end{tabular}

compared to near the basin-edge with increase of quality factor, reflects the effects of sediment-damping on the BGR-waves.

\section{Effects of angle of incidence of body wave}

To quantify the effects of angle of incidence of body waves on the characteristics of BGR-waves, seismic responses of the considered CRAM1-CRAM3 basin models having angle of incidence of body waves as $0^{\circ}, 20^{\circ}$ and $45^{\circ}$ was computed (Fig. 11). The 

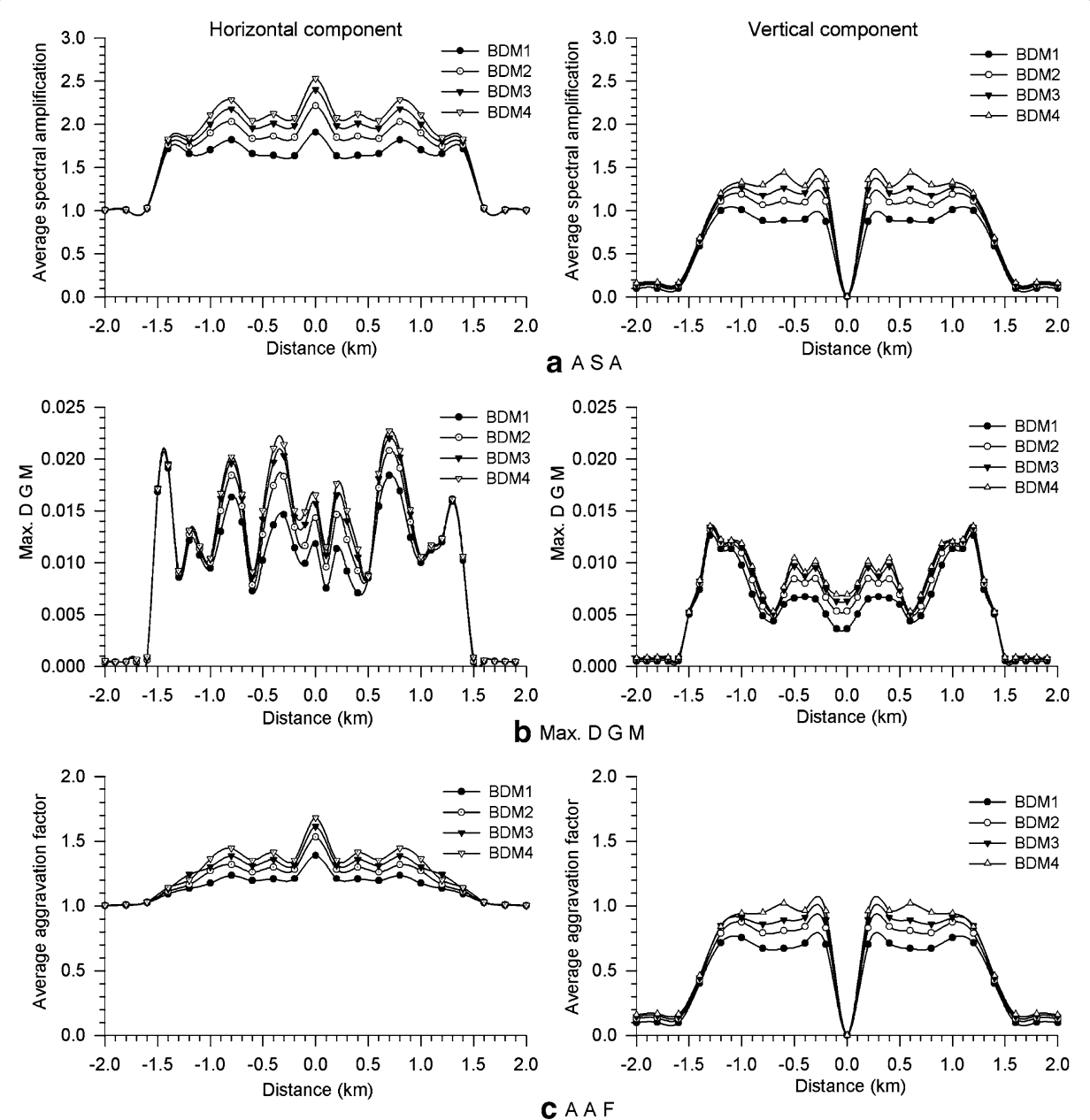

Fig. 10 a-c Spatial variations of ASA, maximum DGM and AAF, respectively in the BDM1-BDM4 basins

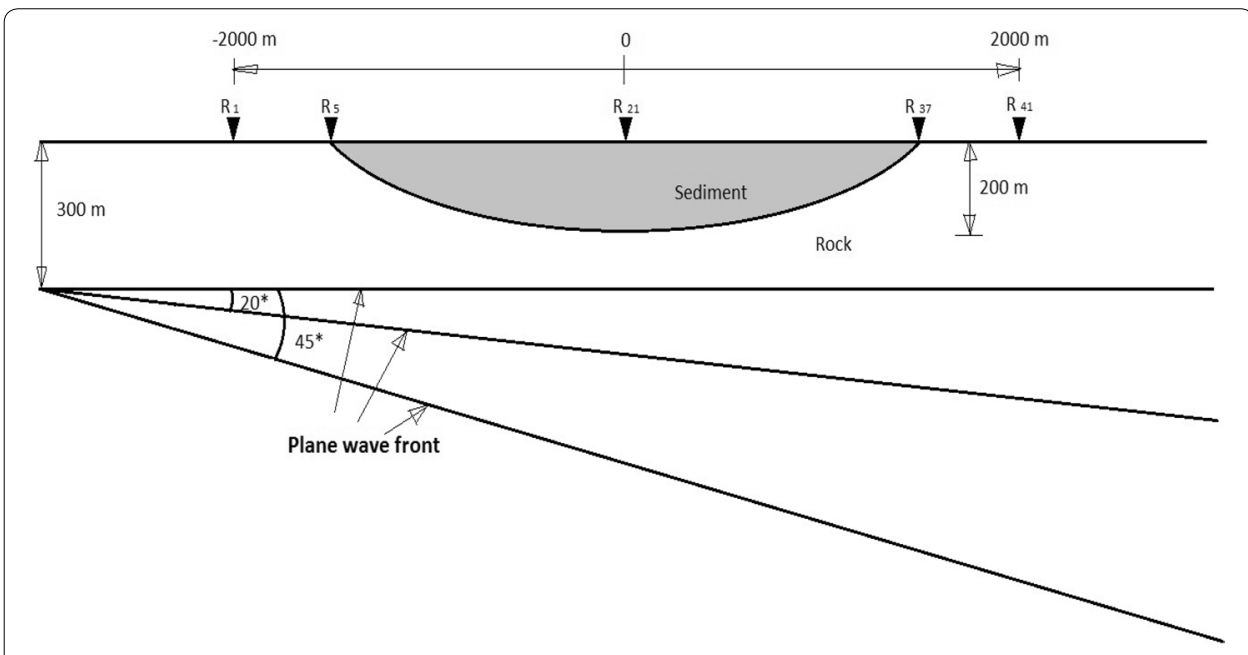

Fig. 11 The CRBM basin model with $0^{\circ}, 20^{\circ}$ and $45^{\circ}$ angle of incidence of plane wave fronts of body wave at the free surface 
considered CRAM1-CRAM3 basin models have IC corresponding to the ICM1 basin model (Table 2). The remaining parameters for the CRAM1-CRAM3 basin models are same. Figure 12a, b show the seismic responses of the CRAM2 basin model without and with basin in the model, respectively. Similarly, Fig. 12c, d show the seismic responses of the CRAM3 basin model without and with basin in the model, respectively. An analysis of Fig. 12a reflects that the inclined $\left(20^{\circ}\right.$ angle of incidence with horizontal) linear body wave front has generated both the P- and S-waves. Furthermore, both the P- and $\mathrm{S}$-waves have caused the BGR-waves in the basin (Fig. 12b). However, the amplitude

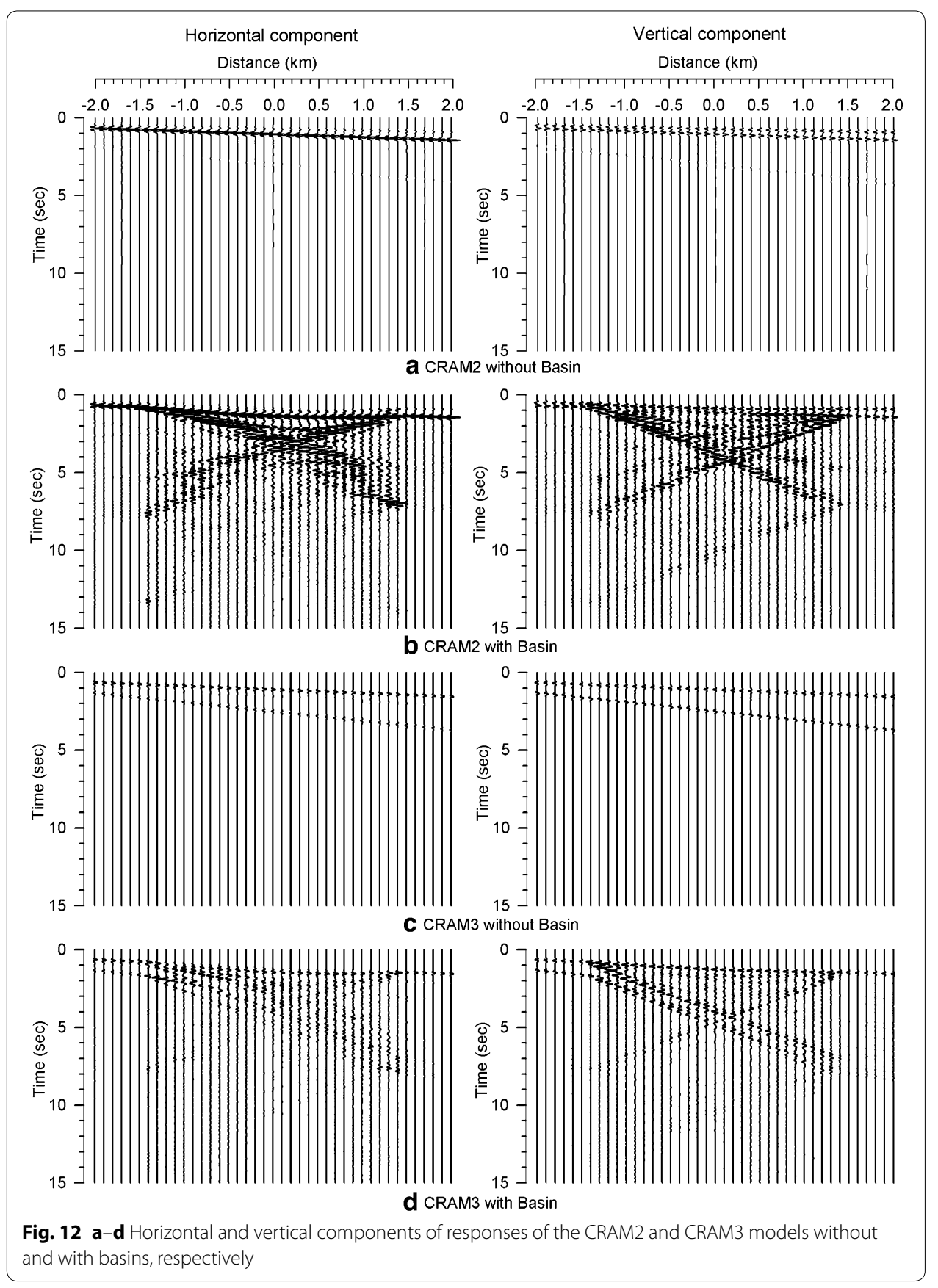


of Rayleigh wave caused by the P-wave is too less as compared to that caused by the incident SV-wave. Similarly, an analysis of Fig. 12c reflects that the inclined ( $45^{\circ}$ angle of incidence with horizontal) linear body wave front has generated mainly P-wave and the amplitude of generated S-wave is negligible. Further, because of large angle of incidence of the P-wave at the free surface has caused Rayleigh waves at the point where the P-wave front first interacted with the free surface [32]. The incident P-wave and the generated Rayleigh wave in the homogeneous rock are the first and second arrivals in Fig. 12c. The generation of Rayleigh wave can also be inferred from Fig. 12d, since there are no Rayleigh wave recording after the basin (right part of figure). It means, in case of the CRAM3 basin model there are both the BGR-waves due to an incident P-wave in basin as well as basin transduced Rayleigh wave (the basin transduced Rayleigh waves are the Rayleigh waves which have been generated in the homogeneous rock by incident P-wave and propagated towards the basin and have now entered into the basin). An increase of amplitude of the basin-transduced Rayleigh wave in the basin can be inferred $[15,16]$. The basin-transduced Rayleigh wave and BGR-wave have caused tremendous increase of amplitude in the basin, particularly in the vertical component. A complex mode conversion of basin transduced Rayleigh wave at the basin edge can also be inferred [15].

Figure 13a-c depicts the comparison of spatial variations of ASA, maximum DGM and AAF, respectively for the CRAM1-CRAM3 basin models, respectively. Analysis of Fig. 13 depicts that there is an increase of ASA, DGM and AAF with an increase of angle of incidence of body wave front. Further, this increase is much larger in case of the vertical component. Similar, conclusion was also drawn by Narayan [23] based on the SHwave modeling. But, the amplification of vertical component in case of the P-SV wave modeling is much larger than that in the $\mathrm{SH}$-wave modeling. Furthermore, the ASA and DGM in the vertical component is largest towards the left edge of basin in case of the CRAM3 model and reverse is the case in the CRAM2 model. In contrast to this, the largest ASA and DGM in the horizontal component is towards the left edge of the basin in both the CRAM2 and CRAM3 models. On the other hand, the amplification of both the horizontal and vertical components is symmetrical around the centre of the basin in the CRAM1 basin model. This is due to the normal incidence of the body waves. The largest values of ASA and AAF in the CRAM3 model were of the order of 7.3 and 4.7, respectively near the left edge of the basin which is much larger than that reported by Narayan [23] in case of SH-wave response. This is due to the combined effects of both the basin transduced Rayleigh wave and the BGR-wave. Finally, it may be concluded that amplification of ground motion increases with the increase of angle of incidence of body waves in both the components but it is much larger in the vertical component. The obtained very large AAF (4.7) in case of the CRAM3 model may be due to the development of large amplitude Rayleigh by the incident P-wave in the homogeneous rock and their propagation and entering into the basin.

\section{Conclusions}

The analysis of horizontal and vertical components of P-SV wave responses of the various considered 2D semi-circular, rectangular, triangular and trapezoidal basin models revealed that the ground motion in the basin is highly dependent on the SISB and 

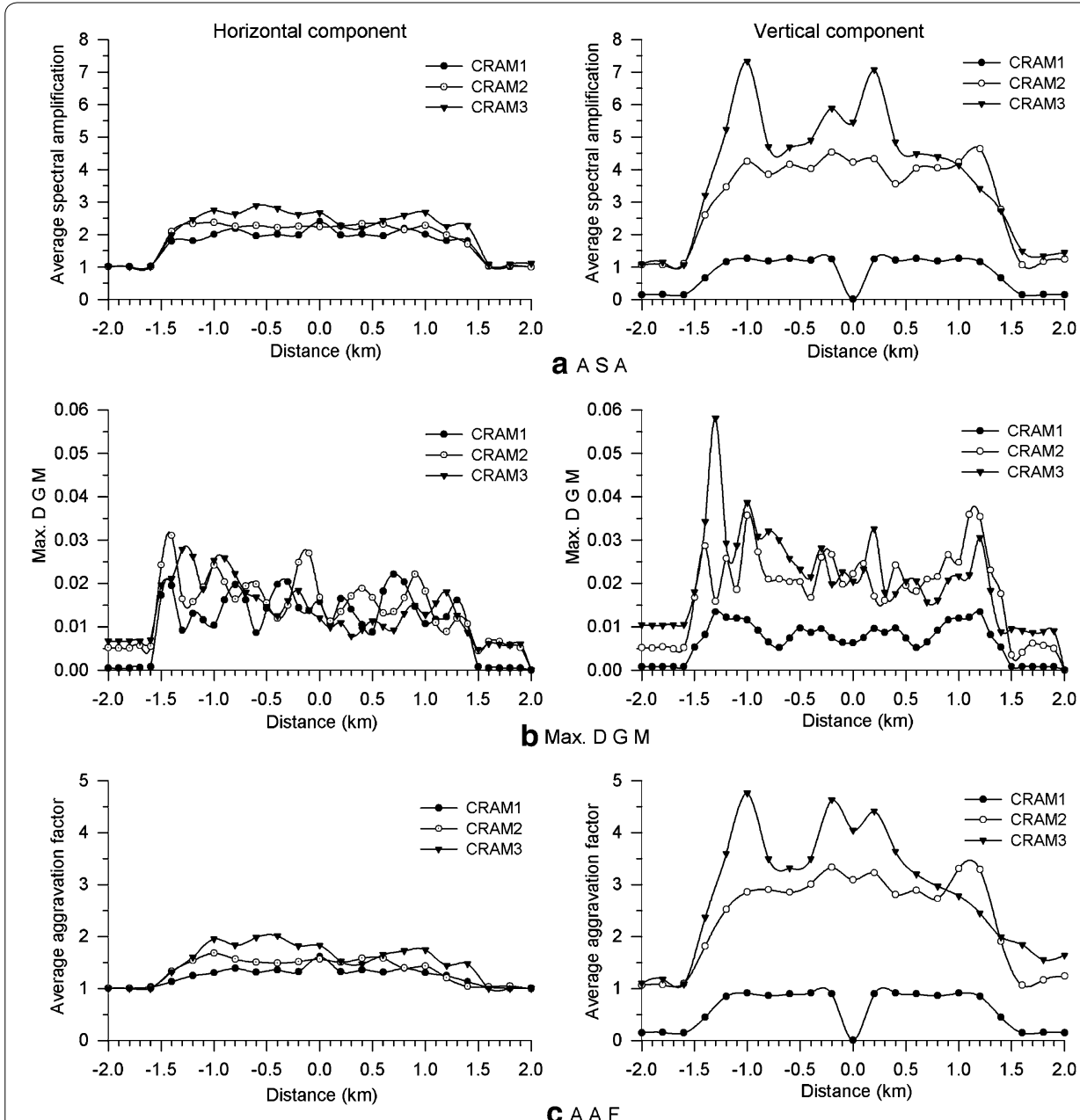

Fig. 13 a-c Spatial variations of ASA, maximum DGM and AAF, respectively in the CRAM1-CRAM3 basins

shape-ratio. The obtained ASA, DGM and AAF were largest in the triangular basin and least in the trapezoidal basin for the considered model parameters. The ASA, DGM and AAF in the rectangular and trapezoidal basins were larger near the basin-edge $[7,31]$ and these were lager near the centre of the triangular and semi-circular basins. An increase of ground motion amplification in the form of ASA, DGM and AAF was obtained with an increase of shape-ratio of the basin (in the range 0.03-0.16). On an average, an increase of ASA, DGM and AAF were also obtained with an increase of IC, sediment quality factor.

An increase of amplitude of the BGR-waves with an increase of angle of incidence of body wave was observed. Similar, conclusion was also drawn by Narayan [23] based on the $\mathrm{SH}$-wave responses of the basin for different angle of incidence of the $\mathrm{SH}$-wave front. But, the amplification obtained in the vertical component is much larger in the P-SV wave modeling as compared to the $\mathrm{SH}$-wave modeling. In case of inclined wave fronts (CRAM2 and CRAM3 basin models), the obtained ASA DGM and AAF in the vertical component is much larger than that in the horizontal component and this difference is increasing with an increase of angle of incidence of body wave fronts. Furthermore, the 
obtained very large AAF (4.7) in case of the CRAM3 basin model may be also due to the basin transduced Rayleigh wave [16, 32]. Means, both the basin transduced Rayleigh wave and the BGR-wave are reason behind obtained very AAF in the CRAM3 basin model.

\section{Authors' contributions}

JPN supervised the research work and participated in amending the manuscript. Kamal helped PKS to some extent to carry out the numerical simulations, analyzing results and drafting the manuscript. All authors read and approved the final manuscript.

\section{Acknowledgements}

The second author is thankful to Ministry of Human Resource Development (MHRD), New Delhi for providing the Scholarship during the tenure of his M.Tech. course study at IIT Roorkee.

\section{Competing interests}

The authors declare that they have no competing interests.

Received: 28 May 2016 Accepted: 28 September 2016

Published online: 07 October 2016

\section{References}

1. Dobry R, Vucetic M (1987) State-of-the-art report: dynamic properties and response of soft clay deposits. Sociedad Mexicana de Mecanica de Suelos 2:51-87

2. Narayan JP, Sharma ML, Kumar A (2002) A seismological report on the January 26, 2001 earthquake at Bhuj, India. SRL 73:343-355

3. Bard PY, Bouchon M (1980) The seismic response of sediment-filled valleys. Part 1. The case of incident SH waves. Bull Seismol Soc Am 70:1263-1286

4. Graves RW, Pitarka A, Somerville PG (1998) Ground motion amplification in the Santa Monica area: effects of shallow basin edge structure. Bull Seismol Soc Am 88:1224-1242

5. Hatyama K, Matsumami K, Iwata T, Irikuna K (1995) Basin- induced love wave in the eastern part of the Osaka basin. J Phys Earth 43:131-155

6. Kawase $H$ (1996) The cause of the damage belt in Kobe. 'the basin-edge effect,', constructive interference of the direct S wave with the basin-induced diffracted/Rayleigh waves. SRL 67:25-35

7. Narayan JP (2005) Study of Basin-edge effects on the ground motion characteristics using 2.5-D modeling. PAGEOPH 162:273-289

8. Narayan JP, Singh SP (2006) Effects of soil layering on the characteristics of basin-edge induced surface waves and differential ground motion. J Earthq Eng 10:595-614

9. Pitarka A, Irikura K, Iwata T, Sekiguchi H (1998) Three-dimensional simulation of the near fault motion for the 1995 Hyogoken Nanbu (Kobe), Japan, earthquake. Bull Seismol Soc Am 88:428-440

10. Booth DB, Wells RE, Givler RW (2004) Chimney damage in the greater Seattle area from the Nisqually earthquake of 28 February 2001. Bull Seismol Soc Am 94:1143-1158

11. Gao S, Liu H, Davis PM, Knopoff GL (1996) Localized amplification of seismic waves and correlation with damage due to the Northridge earthquake. Bull Seismol Soc Am 86:S209-S230

12. Narayan JP, Kumar V (2014) P-SV wave time-domain finite-difference algorithm with realistic damping and a combined study of effects of sediment rheology and basement focusing. Acta Geophys 62:1214-1245

13. Kawase H (1993) Effects of surface and subsurface irregularities in Earthquakes and ground motions, Part I, Ch. 3 Section 3.3. Architectural Institute of Japan, Tokyo, pp 118-155

14. Narayan JP (2010) Effects of impedance contrast and soil thickness on the basin transduced Rayleigh waves and associated differential ground motion. PAGEOPH 167:1485-1510

15. Narayan JP (2012) Effects of P-wave and S-wave impedance contrast on the characteristics of basin transduced Rayleigh waves. Pure Appl Geophys 169:693-709

16. Narayan JP, Kumar R (2014) Spatial spectral amplification of basin-transduced Rayleigh waves. Nat Hazards 71:751-765

17. Poceski A (1969) The ground effects of the Skopje July 26, 1963 earthquake. Bull Seismol Soc Am 59:1-22

18. Semblat JF, Kham M, Parara E, Bard PY, Pitilakis K, Makra K, Raptakis D (2005) Site effects: basin geometry vs soil layering. SDEE 25(7-10):529-538

19. Chavez-Garcia FJ, Faccioli E (2000) Complex site effects and building codes: making the leap. J Seismol 4:23-40

20. Narayan JP, Kumar S (2009) Effects of soil layering on the characteristics of basin-edge induced surface waves and associated spatial variability and aggravation factor. Acta Geophys 57:294-310

21. Kumar S, Narayan JP (2008) Importance of quantification of local site effects based on wave propagation in seismic microzonation. J Earth Sci Syst 117(S2):731-748

22. Narayan JP, Richharia Alka A (2008) Effects of strong lateral discontinuity on ground Motion characteristics and aggravation factor. J Seismol 12:557-573

23. Narayan JP (2012) Effects of angle of incidence of SH-wave on the characteristics of SLD-induced Love waves. J Earthq Tsunami 6:1250006(1)-1250006(21). doi:10.1142/S1793431112500066) 
24. Emmerich H, Korn M (1987) Incorporation of attenuation into time-domain computations of seismic wave fields. Geophysics 52(9):1252-1264

25. Kristeck J, Moczo P (2003) Seismic wave propagation in viscoelastic media with material discontinuities - a 3D 4th order staggered grid finite difference modeling. Bull Seismol Soc Am 93:2273-2280

26. Narayan JP, Kumar V (2013) A fourth-order accurate finite-difference program for the simulation of SH-wave propagation in heterogeneous viscoelastic medium. Geofizika 30:173-189

27. Futterman WI (1962) Dispersive body waves. J Geophys Res 67(13):5279-5291. doi:10.1029/JZ067i013p05279

28. Israeli M, Orszag SA (1981) Approximation of radiation boundary conditions. J Comp Phys 41:115-135

29. Kumar S, Narayan JP (2008) Implementation of absorbing boundary conditions in a 4th order accurate SH-wave staggered grid finite difference program with variable grid size. Acta Geophys 56:1090-1108

30. Narayan JP, Kumar S (2008) A (2, 4) parsimonious staggered grid SH-wave FD algorithm with variable grid size and VGR-stress imagining technique. PAGEOPH 165:271-295

31. Moczo P, Bard PY (1993) Wave-diffraction, amplification and differential motion near strong lateral discontinuities. Bull Seismol Soc Am 83:85-106

32. Narayan JP, Kumar S (2010) Study of effects of focal depth on the characteristics of Rayleigh waves using finite difference method. Acta Geophys 58:624-644

\section{Submit your manuscript to a SpringerOpen ${ }^{\circ}$ journal and benefit from:}

- Convenient online submission

\section{- Rigorous peer review}

- Immediate publication on acceptance

- Open access: articles freely available online

- High visibility within the field

- Retaining the copyright to your article

Submit your next manuscript at $\boldsymbol{\nabla}$ springeropen.com 